\title{
Technology Enhanced Construction Technology Teaching
}

\author{
Alex Amato, Ruffina Thilakaratne \\ Department of Architecture \\ James Henri, Sue Trinidad \\ Faculty of Education, Division of Information and Technology Studies \\ The University of Hong Kong- Pokfulam Rd., Hong Kong
}

\begin{abstract}
Design studio has been the heart of architectural education since late $18^{\text {th }} C$ and thus students often consider other courses as peripheral to studio. In a majority of schools, the nature of the design studio pedagogy and the way that other courses are taught appear as two systems. Courses 'supporting studio' have been very much a teacher-centred didactic exercise, traditionally delivered in lectures.

Understanding this background, this study examined the success of teaching technical courses such as construction technology by adapting different strategies mediated through a web-based approach. This paper reports the findings of the study funded by The University of Hong Kong and the Universities Grants Commission of Hong Kong.
\end{abstract}

\section{Project aims}

This project began with an investigation of deficiencies, from both student and teacher perspectives in tectonics teaching. The project aim was to reinforce these deficits by adopting new pedagogical practices and authentic forms of assessment. 'Tectonics', a three credit core course, offered in all years of the BA(AS) was chosen as a suitable pilot course to promote enquiry and innovation. 'Tectonics' combines environmental science and services, structures and construction technology, offered by a team of three teachers. However, for this study only the construction technology course was considered.

A comparative analysis of traditional teacher-centred pedagogy and recently evolved student-centred pedagogies, was carried out and the outcome was to shift the focus of instruction from teacher to the student. This was achieved by embedding pedagogies and tools such as problem based learning (PBL), creating online forums, learning communities, virtual construction sites with a high visual emphasis and integrated projects. Problem based learning and project based learning (PBL); are student-centred methodologies that underpin active learning and are well known by academics in the fields of architecture and education.

Visual emphasis in course content is essential, because Hong Kong students have little practical personal experience of construction and thus do not possess an intuitive understanding of building. Moreover text books written in English and not in Cantonese compound this problem. Thus explaining even relatively simple construction processes is extremely difficult task unless demonstrated by excellent visual materials. This paper reports the new pedagogical initiatives and their implications on students' construction technology learning.

\section{Background}

An analysis of previous experience revealed a considerable activity in the field of tectonics overseas and even at the University of Hong Kong. The review cited some examples of student-centred learning that include Integrated Problem Based Learning where all courses are taught through design projects [9], online case studies that simulate construction environments and gaming approaches [2, 3]; and learning by doing approaches [5, 8]. Several researches related to construction education were reported from Hong Kong: City University, Chinese University, Polytechnic University and the University of Hong Kong. In 1991, researchers [10, 11] had investigated innovative approaches to improve construction education at the University of Hong Kong. However, because these projects were isolated, with poor dissemination of the findings and very little interdepartmental collaboration, the impact in changing pedagogical practice was slight. 
Having completed a review of relevant work, a curriculum mapping process was undertaken. Findings indicate that there is little opportunity for interdepartmental collaboration within the University. However, the desire to review the tectonics curriculum within the department was opportune and this became the pilot course for this research. Graduate attributes were thus developed for the proposed tectonics course using a sound research framework [6, 7]. An online Learner Management System was chosen as a platform for delivery (http://iln.cite.hku.hk) for semesters 1 and 2, $2003 / 2004$. Researchers worked closely with teaching staff, to facilitate the use of the new teaching material that had been developed, tracking its use as well as the new teaching/learning process.

\section{Design studio vs. lectures}

Architecture design studios present a unique learning culture where students learn through their own projects and by doing. Schön [4] describes the architectural studio as a source of insight into education for reflection-inaction. In the studio, students present design ideas to their tutors and peers using different communicable visual media and learn from a two way discussion process, with students baring the responsibility for their learning.

Students consider design studio to be of more importance than other courses due to its high credit load, time allocation and the central ideological position it holds in the perception of what an architect does. Consequently in studio, student initiative and preparation is significant compared with traditional lectures and architecture students are more used to this type of learning than listening in lectures.

Contrary to design studio (a student-centred pedagogy) other courses are offered in a traditional teacher-led environment allowing little interaction during the lesson. The purpose of these lectures is to provide students with an education in design and architecture and with the professional knowledge they will require in their careers.

There is an assumption, in nearly every architecture school, that knowledge is transferred from lectures and applied in design studio. This assumption has probably existed for over fifty years and it is our contention that it has never been adequately validated. Furthermore our experience within the department at $\mathrm{HKU}$, is that this does not work for construction technology and consequently there is an absence of any appropriate mechanisms to ensure proper application and integration of construction technology in design.

Although teaching in design studio is a pioneering model of student-centred learning, this approach has not been fully absorbed into the rest of the curricula. This is not surprising given the presumption prevalent in most architecture schools about the transfer of knowledge from lectures to studio. Although students are competent in their design thinking, they are poor in applying knowledge from other courses.

\section{Our approach}

Comparing the potentials of student-centred and teacher-centred pedagogies, we adopted a hybrid approach: a combination of student-centred and teachercentred pedagogies. Innovative curriculum materials were developed following the "linking learning with assessment" cycle [7]. This cycle follows a process where assessment drives the learning, which is the vehicle for the construction of knowledge.

The curriculum material consisted of self-learning resources, supplementary teaching material, clinics (a mini lecture series conducted by invited speakers), case study presentations and quizzes. This demanded the change in teaching culture as well as its structure. Mounting these innovations within a Learner Management (LMS) supported a community of learners and provided a platform for the extensive use of digital resources, data sharing, social interaction and information exchange. The trial course was delivered in a traditional face-to-face setting but supplemented with an in-house developed LMS; Interactive Learner Network (ILN). ILN is a community-building environment designed to support virtual education communities of practice where teachers/students engage in reflective, collegial patterns of work.

This environment is designed to support academic programs that rely heavily on pedagogies that emphasize the emergence and growth of autonomous collaborative learning, rather than teacher-directed delivery of learning materials (see http://iln.cite.hku.hk/). In this way, technology was used to support these new pedagogical practices.

\section{Progress and findings}

Our findings indicated both strengths and weaknesses of the innovative and integrated approaches adapted in teaching construction technology and helped us to set directions for future development. Students' evaluations indicated the overall success of these initiatives.

Teachers had difficulty moving away from a traditional teacher's role to a facilitator's role and continued to practice a heavily teacher-centred system. There was little interaction and coordination among the teachers who committed to work independently practicing 
their own teaching styles, limiting the cross-fertilization of good practice.

One of the project aims was to link teaching with learning outcomes and assessment. Teachers were expected to inform the students about the expected learning outcomes at the beginning of the session and to make sure that these objectives were met at the end. However these changes were not apparent in the process. These shortcomings were because teachers were not adequately trained to deliver the new pedagogy. Although students responded to these changes and demonstrated considerable initiative, they still expected even more guidance from the teachers.

\section{Integrated studio}

The integration of construction technology with studio design projects is relatively novel. This innovation delivered sound learning outcomes and appraisal from both students and teachers. Crucial to this process was the desire to integrate knowledge in architectural design. Assessment tasks developed under this approach demanded students to research, analyse, synthesise and apply knowledge. Students were expected to present evidences for their findings and inspirations. These outcomes were assessed through assessment rubrics that were made available to students at the beginning of the process. It is essential to allow sufficient time for the students to carry out the required research, assimilate the knowledge and apply this within the studio programme. This requires the teachers to carryout realistic assessment of workload and then coordinate the curriculum to avoid major clashes of workload peaks.

In architecture schools, project-based course work and studio assessment has always been based on subjective criteria, i.e. the teachers' experience. For many years design studio assessment has been the subject of world wide debate amongst architectural educators [1]. In our project, assessment was tackled by developing rigorous assessment rubrics. The assessments were expected to be carried out by both design and tectonics teachers together based on well developed rubrics. Despite these complicated procedures, students work output indicated positive results. Students' designs were not only rich in design thinking, but also sound in construction technology aspects. Some students applied their construction technology knowledge to invent new design ideas or to solve problems. Figure 1 illustrates the application of construction technology knowledge when designing a place for music performance (Fig. 1).

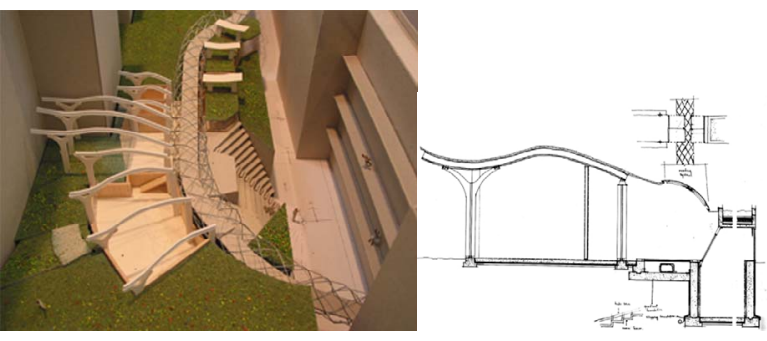

Figure 1. Integration of construction technology in design projects

\section{LMS-Interactive Learner Network}

A LMS means much more than depositing and delivering material via the Internet. It provides the potential to create an interactive learning environment, group work, communication with peers and teacher. However the usefulness of this system for in-class activities is dependent upon the support infrastructure of this department. Due to the lack of suitable tutorial spaces equipped with computers, the potential of the LMS for inclass activities and the ensuing changes to teachers and students' attitude could only be partially explored. However some features of the LMS such as online quizzes, online forum, course work submission, and resource management made a significant contribution to the course delivery and to students learning.

\subsection{Online forum in ILN (LMS)}

The introduction of the online forum immediately affected the students' learning and some teachers' practice. Positive signs emerged through the online forum as HK students are usually passive in front of their teachers but use to the e-culture of chat rooms, participated with some gusto.

There was emerging evidence that ILN encourages students to be more interactive and communicative learners through the forum and began to exhibit more independent and self-reflective problem solving behavior. Much students and staff interaction happened on the online forum indicating students' active role in self learning, e.g. sustainability forum. Students discussed their ideas further through the online forum with 187 postings over 12 weeks and demonstrated analytical and logical reasoning skills that are very significant to the learning and practice of architecture.

This public forum helped the teachers to interact more with the students and to holistically understand students' views about the new proposals. However the enthusiasm started to fluctuate due to various other factors such as course work submission, time constraints and lack of structure and specifications about the forum participation. 
The frequency of forum participation in the semester one ranged over a thirteen week period, from 0-73 visits per week to the forum with a peak during the first four weeks of the semester (Fig. 2a). Forum participation in the semester two indicates a different trend with a peak from week seven to fourteen (Fig. 2b).

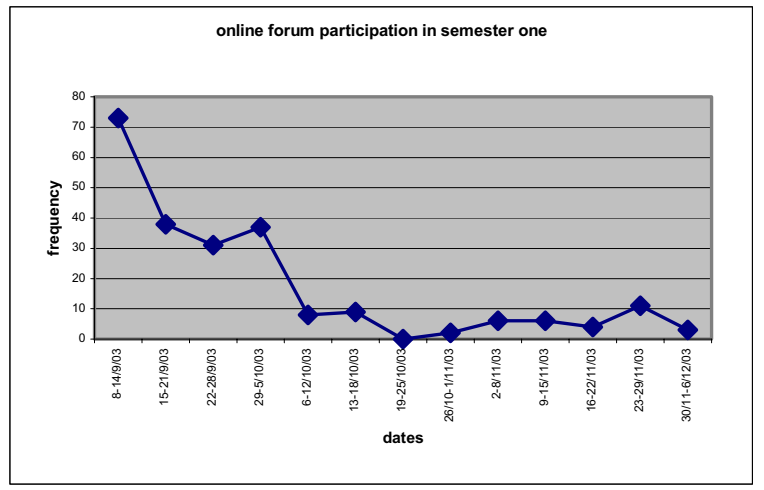

Figure 2a. Online forum participation by students and teachers in the semester one

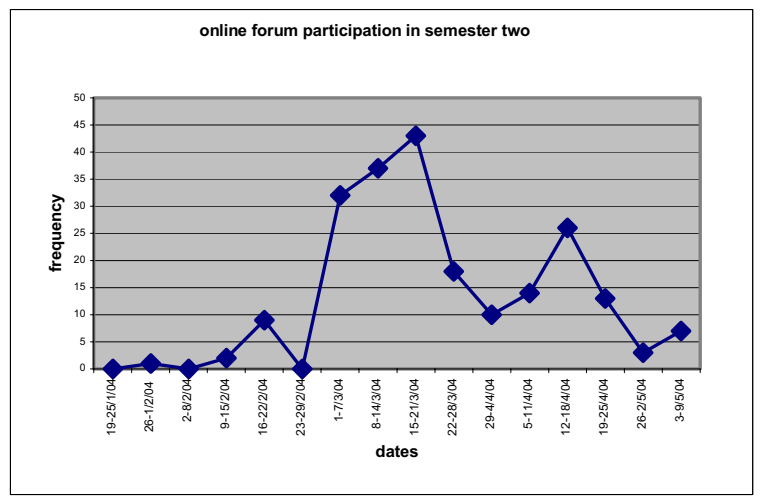

\section{Figure $\mathbf{2 b}$. Online forum participation by students and teachers in the semester two}

Forum in the semester two was based on subject specific topics, whereas the forum in the semester one was based on students comments about the course. Thus the forum in the semester two not only had a high frequency of participation but also demonstrated intense discussions with the introduction of structured topics such as "sustainable architecture" preceded by case study group presentations and clinics. Students and teachers were actively involved in discussing issues related to the programme and subject content outside regular class hours indicating a high level of interaction.

\subsection{Online quizzes}

The objective of the online quizzes is to encourage self-learning by cultivating a culture of reading and to ensure that the students are prepared for the lecture. Students' high performance and high level of participation in online quizzes and their positive comments are evidence of the success of this approach. Fig. 3 indicates the high rate of attendance in quizzes compared to their attendance in lectures. The level of quiz attendance and class attendance also decreased when lessons clashed with other course assignments. Higher attendance level in drawing sessions indicates students' enthusiasm in such activities. However these shortcomings were eliminated when planning the second semester by integrating in-class assessment tasks during the lecture to encourage participation. These assessment tasks include, role play, drawing exercises, model building, video-based discussions etc.

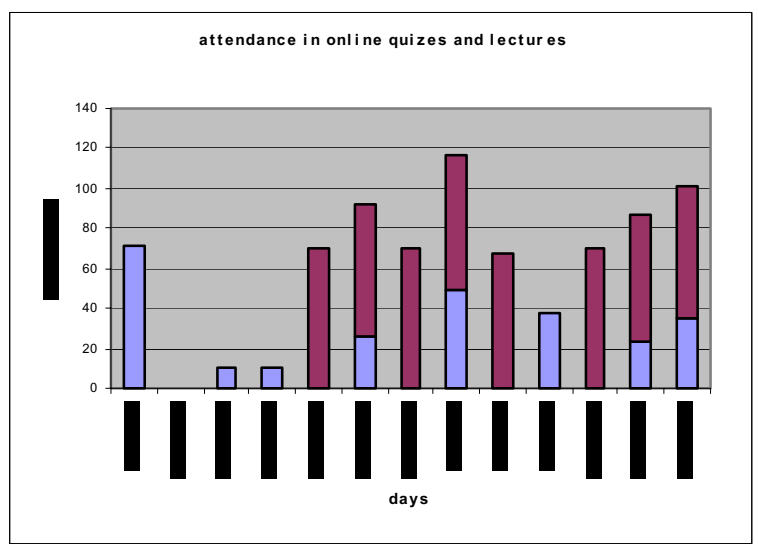

Figure 3. A comparison of attendance in lectures and online quizzes (lectures; quizzes)

One of the constraints in web-delivered programs is the difficulty of controlling access, e.g. impersonation. The mismatches between students' attendance and quiz participation results indicate that some students have accessed the quiz remotely. However this was regarded as an indication of their self-learning behavior.

\section{Conclusions}

A combination of teacher and student-centred approaches were implemented.

An LMS such as ILN requires teachers to make their teaching resources available for students and students are required to be more accountable for their learning. The online forum and online quizzes were the most attractive features of the innovation for both students and staff. Forum participation improved with more structured 
discussion topics. Students became active learners through the forum began to cultivate a culture of peer learning indicating the potential for a predominantly student-centred learning. ILN received positive appraisal from students as it allows them to download resources from any where at any time. It also allows for communication with teachers, peers outside regular class hours and submit their assignments online. ILN provided a systematic way of managing teaching resources, posting announcements, auto reminder service that alerts deadlines, tracking the usage and participation in various functions and enabling instant feedback for the development and evaluation of the system and the programme.

However there is strong evidence that the following developments need to be made in order to reach more positive outcomes from these initiatives:

-A policy within the department or a reward structure to shift teachers' attitude from a teacher towards a facilitator -Coordination among teachers regarding assignment hand-in dates

-In-class activities to create interactive and participatory learning and improve students' attendance

-Design reliable instruments to ensure and assess students learning

-Infrastructure to support interactive learning environment within lecture rooms

On the whole these new initiatives have been successful and indicated positive changes in students learning behaviors: maturity, responsibility, self motivation and their potential for self-learning that is enhanced by technology and visual aids.

\section{References}

[1] Anthony, K., Design Juries on Trial: The Renaissance of the Design Studio, Van Nostrand Reinhold, New York, 1991.

[2] Batie, D.L. and E. Connell, "Developing a design/build internet class: communication, communication, communication", Journal of Construction Education, 2000, Summer, pp. 123-133.

[3] Ham, J., "The reflective making of 'games' for Construction Education, playful learning design forum",in http://www.arch.adelaide.edu.au/games/forum/index.html/ Retrieved 05/08/2003, 2001.

[4] Schon, D., The Design Studio: An Exploration of its Traditions and Potentials, RIBS Publications Ltd, London, 1985.
[5] Tan, W. and Y. Elias, "Learning by doing in Singapore Construction", Journal of Construction Research, 2000, Sept.

[6] Trinidad, S., "Working in technology rich learning environments: strategies for sustainable success", in Technology-rich Learning Environments, D. Fisher and M. KhineSwee, Edt., World Scientific, Singapore, 2003, pp. 97-113.

[7] Trinidad, S. and R. Albon, Using the Potential of Technology to Reconceptualise Assessment, Common Ground Publishing, Australia, 2003.

[8] University of Adelaide, "School of Architecture, Landscape Architecture \& Urban Design", in http://www.arch.adelaide.edu.au/abe/ Retrieved 11 Aug. 2003, 2001.

[9] University of Newcastle, "School of Architecture and Built Environment Homepage", in http://eng.newcastle.edu.au/abe/ Retrieved 31 July 2003, 2000.

[10] Walker, A., K.G. McKinnell, and K.W. Chau, "Towards a common education in construction and real estate", in Special Edition on Education for Construction Management, Dept. of Real Estate and Construction, The University of Hong Kong, 1996.

[11] Will, B.F. and J.W. Bradford, "Interactive Teaching in the Field of Architecture to Research and Develop Interactive Programmes at Learning Utilizing Multimedia Computer Technology", Internal Working Paper, Hong Kong University, Hong Kong, 1991. 